\title{
Avaliação epidemiológica da prevalência da hematúria enzoótica bovina associada a samambaia no Paraná
}

\author{
Daniel Augusto da Silva1, André Hiroshi Quadros Watanabe², Wilmar Sachetin \\ Marçal $^{3 *}$ \\ ${ }^{1}$ Graduando em Medicina Veterinária pela Universidade Estadual de Londrina. Rua Olavo Bilac, 492, jd. Champagnat, \\ Londrina - PR. cep: 86062-260. \\ ${ }^{2}$ Bolsista do projeto ESCOLA DE CAPATAZES da Universidade Estadual de Londrina. \\ ${ }^{3}$ Professor Associado na Universidade Estadual de Londrina. Docente Orientador. \\ *Autor para correspondência: wilmar@uel.br
}

\begin{abstract}
RESUMO. A Hematúria Enzoótica Bovina é uma enfermidade decorrente da ingestão da samambaia, acometendo os animais em quase todos os estados do Brasil. Devido aos prejuízos econômicos e ao risco à saúde pública, as pesquisas continuam buscando formas de controle da planta e da enfermidade, já que há localidades onde ainda se criam bovinos em contato direto com a planta, principalmente no estado do Paraná. Em outro viés, há muitos técnicos extensionistas empenhados em conscientizar os produtores rurais que continuam desafiando a ciência, acreditando que a hematúria enzoótica não tem relação direta com a samambaia. Sugerem outras etiologias, argumentam profilaxias caseiras e vivem de empirismo terapêutico. Enquanto isso, a planta ainda continua presente em vários municípios e a manifestação de quadro hemorrágico característico e peculiar nos bovinos cresce a olhos vistos. Tal situação é muito presente em localidades ocupadas pelos bovinos onde a topografia é bem acidentada, sem possibilidade de mecanização da terra. Aliado a isso, há evidente falta de política subsidiária do governo em propiciar a calagem do solo, para correção da acidez provocada pelo excesso de alumínio. Assim exposto, num amplo levantamento em municípios paranaenses, detentores da samambaia em suas pastagens, os autores correlacionaram a existência da planta a manifestação natural de Hematúria Enzoótica dos Bovinos para, num momento futuro e oportuno, conseguirem sensibilizar os produtores rurais para o controle da planta, eliminação da enfermidade e maior segurança a saúde pública, consumidora dos subprodutos de origem animal, como carne e leite.
\end{abstract}

Palavras chave: Bovinos, hematúria, intoxicação, samambaia

\section{Evaluation of the epidemiological bovine enzootic haematuria associated with prevalence of bracken fern in Paraná state}

\begin{abstract}
The Bovine Enzootic Haematuria is a disease resulting from bracken fern intake, affecting animals in almost all states of Brazil. Due to economic losses and the risk to public health, research continues looking for ways to control plant and illness, as there are still places where cattle are created in direct contact with the plant, mainly in the state of Parana. In another perspective, many field workers engaged in awareness among farmers that continue to challenge the science, believing enzootic haematuria has no direct relationship with the bracken fern. They suggest other etiologies, argue homemade prophylaxis and live therapeutic empiricism. Meanwhile, this plant is still present in several municipalities and the manifestation of characteristic and peculiar hemorrhagic in cattle grows visibly. This situation is very present in places occupied by cattle where the topography is quite rugged, with no possibility of land mechanization. Allied to this, there is evident lack of government policy in providing subsidiary liming the soil to correct the acidity caused by excess aluminum. Thus exposed, in a comprehensive study on municipal districts, bracken fern holders in their pastures, the authors correlated the
\end{abstract}


existence of the plant to natural manifestation of Bovine Enzootic Haematuria for, a future and timing, get sensitize farmers to control plant, the disease elimination and increased safety public health, consumer of animal by-products such as meat and milk.

Keywords: Bovine, bracken fern, poisoning, haematuria

\section{Introdução}

O Estado do Paraná almeja, de forma constante, alcançar o pico de sua produção agropecuária, especialmente por deter eficiente tecnologia e indiscutível produtividade (Marçal et al., 2004), com um efetivo bovino de 9.413.937 cabeças (ANUALPEC, 2014). Entretanto, demonstra alguns problemas na criação animal, apresentando graves enfermidades relacionadas à ingestão de vegetais tóxicos (Carvalho et al., 2011).

De grande repercussão nesse enfoque, destaca-se a Pteridium aquilinum, planta tóxica popularmente conhecida por samambaia dos campos ou simplesmente samambaia (Tokarnia et al., 1979, Tokarnia et al., 2000), recentemente reclassificada como Pteridium arachnoideum (Thomson et al., 2008). Trata-se de um vegetal de característica invasora, frequente em solos ácidos, arenosos e de baixa fertilidade. É uma planta perene, rizomatosa, herbácea, ereta e ramificada, medindo entre 50 e $180 \mathrm{~cm}$ de altura. Infesta campos, matas ciliares, capoeiras, beiras de matos e de estradas. A remoção da cobertura florestal cria "habitat" ideal para sua invasão (Oinonen, 1967), mantendo-se exuberante em ambientes onde há pouca competição (Polack, 1990), inclusive nas pastagens (Marçal et al., 2004).

Segundo Hojo-Souza et al. (2010) a samambaia encontra-se ainda mais disseminada em função da destruição dos ecossistemas naturais, que foram sendo transformados em extensas áreas agropastoris e agrícolas para atender a demanda da humanidade. Neste contexto, segundo várias informações da mídia brasileira e mundial, áreas florestais que serviam de reserva natural, sofreram desmatamento, destoca e abrigam pastagens sem, contudo ocorrer correção do solo (Marçal, 2000).

A Pteridium arachnoideum tem sido considerada a planta tóxica mais representativa aos prejuízos da pecuária bovina paranaense, ocorrendo em 105 municípios (Polack, 1990), dos 370 estudados (Ferreira, 1996). Relatos de surtos e de ocorrência de problemas com a samambaia afetando rebanhos de bovinos no estado do Paraná já foram observados (Basile et al., 1981, Oliveira et al., 1998, Marçal et al., 2004, Carvalho et al., 2011).

Embora a planta não seja palatável, determinadas condições favorecem sua ingestão pelos bovinos. Em épocas de escassez alimentar, a fome constitui a primeira causa básica de ingestão da samambaia pelos bovinos. Isto normalmente ocorre na estação seca (julho a outubro), pois a planta suporta bem o período sem chuvas, possibilitando sua procura pelos animais. Os animais também podem ingerir os brotos da samambaia, quando houver escassez de pastagens devido à seca, geada, queimada ou mesmo pela superlotação (Parker \& McCrea, 1965). As queimadas não somente possibilitam a sobrevivência, como também criam condições propícias para sua característica invasiva, mesmo em áreas onde a planta ainda não existe. A brotação que surge após as queimadas concentra uma grande quantidade dos princípios tóxicos, tornando-se altamente perigosa para os animais (Marçal et al., 2004, Carvalho et al., 2011).

Segundo alguns estudiosos, os bovinos que ingerem a samambaia acabam "viciados na planta", podendo permanecer com o consumo da planta, mesmo tendo acesso à pastagem natural (Tokarnia et al., 1979), caracterizando, com isso, ingestões repetidas e compulsivas. Outro fator que possibilita que os animais procurem a planta é a carência de pastagem fibrosa. Como a samambaia costuma se desenvolver e atingir boa altura, os bovinos suprem a necessidade de fibra, comendo os caules e folhas longas que a planta normalmente possui. Por fim, os bovinos eventualmente se intoxicam pelo fornecimento de feno contaminado que contenha a samambaia, o que pode ocorrer com animais semi confinados.

Marçal (2000) destaca que, no Brasil, ocorre uma maior manifestação clínica de surtos agudos na época do inverno, devido à escassez das pastagens e pelo fato da samambaia suportar bem a seca. Segundo o autor, a planta tem se disseminado porque encontra condições edafoclimáticas favoráveis para ocupar terras não mecanizáveis, mas que servem como pastagem ao rebanho bovino.

No que concerne à sintomatologia clássica, já em 1942 Goetze apud Reichmann (1975), 
afirmava existir na samambaia além da tiaminase, um veneno vascular causador da diátese hemorrágica. Esta fase clínica da doença é popularmente conhecida por "suor de sangue" (Marçal, 1990; Niero et al., 1991), manifestação clínica de hematidrose (Marçal et al., 2004, Carvalho et al., 2011).

A segunda forma de manifestação da toxidez é conhecida por fase de Hematúria Enzoótica dos Bovinos. As principais características desta fase são evolução crônica, com hematúria intermitente e emaciação. Ocorre perda de sangue, sem reposição pela medula (anemia aplástica), acometendo vacas prenhes e causando abortamento (Marçal et al., 2004, Carvalho et al., 2011).

A terceira forma de manifestação clínica também tem característica crônica, sendo determinada pela formação de carcinomas epidermóides nas vias digestivas superiores (Jankowski et al., 1992), principalmente na base da língua, palato, faringe, esôfago e rúmen de bovinos (Tokarnia et al., 1969). Tais carcinomas epidermóides são popularmente conhecidos por "figueira da goela", "favo" ou "caraguatá". Os bovinos acometidos demonstram emagrecimento progressivo por dificuldade de deglutição, tosse e "ronquidão" ou "ronqueira", isolamento do rebanho, dificuldade respiratória com demasiado cansaço.

Além de intoxicar os animais, sabe-se que a Pteridium arachnoideum é também tóxica ao homem (Tokarnia et al., 1979, Lorenzi, 1982). Na Europa, o consumo de samambaia como alimento humano foi muito utilizado em épocas de deficiência alimentar, como por exemplo, durante a Primeira Guerra Mundial (Ulian et al., 2010). No Japão há um prato típico conhecido por "warabi" que consiste em brotos de samambaia servidos como salada para seres humanos (Marçal, 2003). De acordo com Marliére et al. (1998), no estado de Minas Gerais, mais especificamente em Ouro Preto, a população tem o hábito de consumir os brotos de samambaia. A alta incidência de câncer de esôfago e estômago na região, em relação a outras áreas do estado motivou os autores a investigar a possível influência da ingestão do vegetal na ocorrência daquelas patologias. Foi desenvolvido um estudo retrospectivo de casos e controles baseado em esquema de vigilância epidemiológica estabelecido nos dois únicos serviços de endoscopia da região. Quarenta e seis casos confirmados histologicamente foram pareados com 40 controles que não apresentavam alterações ao exame endoscópico. $\mathrm{O}$ consumo de broto de samambaia foi identificado através de entrevista com os pacientes próximos, em caso de morte. Os autores concluíram neste estudo epidemiológico que houve uma "Odds Ratio", ou seja, razão de chances, fortemente elevada para tumores de esôfago e estômago em pessoas que ingeriram o broto da samambaia.

Galvão et al. (2012) com o objetivo de esclarecer a questão da sobrevida de bovinos afetados por Hematúria Enzoótica, quando transferidos para áreas livres de Pteridium arachnoideum, conduziu um estudo dividido em duas partes, sendo que a primeira foi à aplicação de questionário versando sobre os aspectos epidemiológicos dessa enfermidade, respondido por proprietários de 73 estabelecimentos pecuários visitados nas áreas da Região Sudeste onde Pteridium arachnoideum é prevalente. $\mathrm{O}$ questionário respondido indicou que a Hematúria Enzoótica dos Bovinos (HEB) foi à causa de sérios problemas sócio-econômicos. Em seguida, os autores realizaram um acompanhamento clínico e laboratorial de 51 bovinos daquela região, afetados pela Hematúria Enzoótica entre 2007 e 2011, transferidos para região livre de Pteridium arachnoideum. Desse modo, verificaram que mais de $90 \%$ dos animais afetados por HEB morrem antes de dois anos após serem transferidos para áreas indenes de Pteridium arachnoideum.

Furlan et al. (2014), em pesquisa realizada no Mato Grosso referem que na região norte daquele estado, destacaram que em 40 fazendas, 15 apresentaram problemas com a planta samambaia, inclusive com manifestação de Hematúria Enzoótica dos Bovinos. Segundo os autores, a falta de conhecimento sobre as formas de intoxicação pela planta dificulta a conscientização dos proprietários sobre a importância da enfermidade naquela vasta região, causando impactos negativos na pecuária.

Sabendo-se da importância dessa doença para a saúde pública, para o bem estar animal, dos prejuízos econômicos e de sua ampla disseminação no Paraná, este trabalho buscou levantar informações sobre a distribuição da planta e da HEB em algumas regiões críticas no estado. O mapeamento permitiu delimitar zonas de impacto negativo para a criação de vários bovinos de modo extensivo, além de servir de 
alerta às autoridades sanitárias, pois o destino dos subprodutos de origem animal, como leite e carne, ainda se concentram em ampla oferta aos próprios munícipes.

\section{Material e Métodos}

Para se atingir o objetivo proposto com esse trabalho e abranger a maior parte dos municípios do Estado do Paraná, utilizou-se um questionário sistematizado por via eletrônica, elaborado em conjunto com os técnicos do escritório regional da EMATER em Londrina. O levantamento perdurou por 30 dias para que todos os escritórios tivessem oportunidade de participação e colaboração. Essa dinâmica ocorreu durante o mês de agosto de 2015. Essa estratégia levou em consideração que há uma unidade daquela empresa de extensão em cada um dos 399 municípios oficiais no Paraná. Esta estratégia foi viabilizada a partir das chamadas mesorregiões já definidas pela própria EMATER, sendo em número de oito, a saber: Apucarana, Campo Mourão, Cascavel, Guarapuava, Jacarezinho, Londrina, Pato Branco e Ponta Grossa. A somatória de cidades que abrangem essas mesorregiões totaliza 64 municípios, com perfil agropecuário tradicional e bem estabelecido.

$\mathrm{Na}$ metodologia considerou-se a informação cruzada, prestada pelos técnicos lotados nas respectivas unidades da EMATER no estado do Paraná, sendo: "já se observaram vacas urinando sangue nessas mesmas propriedades rurais?". "Existe a Pteridium arachnoideum ou samambaia em propriedades rurais de seu município?”

Ainda para subsidiar o presente estudo na amplitude pretendida, foi estabelecido o efetivo bovino de cada um dos 64 municípios atendidos, utilizando-se o apoio de órgão oficial no Estado (ADAPAR, 2011).

\section{Resultados e discussão}

Os resultados obtidos no presente trabalho, no qual se verificou a prevalência da Hematúria Enzoótica Bovina associada à samambaia em 8 grandes agrupamentos de municípios do Paraná, são apresentados na Tabela 1. Pode-se constatar que, os valores encontrados indicam que a samambaia está disseminada principalmente nas regiões Central e Nordeste do estado, abrangendo inúmeros municípios. Logo, das 399 cidades do Paraná, cerca de $61(15,4 \%)$, além de três reservas indígenas em Laranjeiras do Sul, Chopinzinho e Coronel Vivida já contam com alguma manifestação do quadro de HEB a presença confirmada da planta.

Muito embora a distribuição e solicitação tenham sido realizadas para todos os 399 municípios interligados em rede pelo sistema EMATER, alguns escritórios não responderam. Desconhecem-se, por enquanto, as razões da ausência de respostas, mas seguramente estudos posteriores poderão evidenciar novos números. Outros municípios $(\mathrm{n}=12)$ responderam de forma incompleta e outros $(n=21)$ informaram outras situações relacionadas à samambaia, que não eram objetivo do trabalho. Essas situações não foram consideradas para não causar efeito diverso no escopo do trabalho. Todavia, o que ficou evidenciado com os resultados alcançados, é de que nos municípios participantes houve a confirmação de correlação da existência da planta com a manifestação natural de Hematúria Enzoótica Bovina, finalidade precípua desse estudo.

\section{Discussão}

Dois aspectos foram imprescindíveis para a realização do presente levantamento. Primeiro deve-se considerar o estudo realizado por Polack (1990), com o qual se evidenciou a ocorrência da samambaia em 105 municípios dos 370 estudados. A outra motivação foi para se esclarecer os produtores rurais de que há uma correlação direta da presença da planta Pteridium arachnoideum com a manifestação de Hematúria Enzoótica. Muitas crendices, mitos e dúvidas ainda persistem sobre esta correlação no meio rural. Alguns criadores acreditam em outras etiologias, sem, contudo possuírem qualquer confirmação técnica e/ou científica, $\mathrm{O}$ fato é que a hematúria enzoótica dos bovinos no Paraná possui como única etiologia a toxidez crônica pela Pteridium aquilinum. Qualquer outra conotação é especulativa e inautêntica.

No levantamento realizado não foi possível conseguir confirmações além dos 62 municípios, embora eles estejam inseridos em mesorregiões de expressiva pecuária e com a existência de samambaia. Contudo, algumas respostas que não foram conseguidas não podem caracterizar a ausência da doença e da planta. Algumas unidades da EMATER tiveram dificuldades em participar do inquérito epidemiológico proposto, por motivos de força maior. Em estudos complementares espera-se que estas informações sejam repassadas e atualizadas. 
Tabela 1. Prevalência da Hematúria Enzoótica Bovina associada à samambaia (Pteridum arachnoideum) em 8 grandes agrupamentos (mesorregiões) de municípios do Paraná.

\begin{tabular}{|c|c|c|}
\hline $\begin{array}{l}\text { Mesorregiões do } \\
\text { Paraná }\end{array}$ & Municípios estudados e população bovina & Total de bovinos \\
\hline Apucarana & $\begin{array}{l}\text { Apucarana, 21714; Manoel Ribas, 50928; Marumbi, 14433; } \\
\text { Ortigueira 160233. }\end{array}$ & 247308 \\
\hline Campo Mourão & Nova Cantu, 48589. & 48589 \\
\hline Cascavel & Guaraniaçu, 140275. & 140275 \\
\hline Guarapuava & $\begin{array}{l}\text { Altamira do Paraná, 62410; Campina do Simão, 12141; Cantagalo, } \\
\text { 36396; Goioxim, 31616; Guarapuava, 53554; Laranjeiras dos Sul, } \\
\text { 53529*; Palmital, 126896; Pinhão, 57149; Pitanga, 90080; Turvo, } \\
\text { 44877; Virmond, 12063. }\end{array}$ & 580711 \\
\hline Jacarezinho & $\begin{array}{l}\text { Barra do Jacaré, 2141; Carlópolis, 29293; Guapirama, 17271; Ibaiti, } \\
\text { 77073; Jaboti, 11482; Jacarezinho, 38877; Japira, 13474; Joaquim } \\
\text { Távora, 38021; Jundiaí do Sul, 40494; Pinhalão 8093; Quatiguá, } \\
\text { 15799; Ribeirão Claro 64575; Ribeirão do Pinhal, 26920; Salto do } \\
\text { Itararé 18240; Santa Amélia, 2649; Santo Antônio da Platina 65683; } \\
\text { São José da Boa Vista 21998; Siqueira Campos, 30839; Tomazina, } \\
\text { 51045; Wenceslau Braz, 24829. }\end{array}$ & 598796 \\
\hline Londrina & $\begin{array}{l}\text { Congonhinhas, 31832; Jataizinho, 10456; Leópolis, 20885; Londrina, } \\
\text { 55000; Nova Fátima 19707; Nova Santa Bárbara, 764; São Jerônimo } \\
\text { da Serra, 42636; São Sebastião da Amoreira, 3199; Sapopema, } \\
\text { 59779; Santo Antônio do Paraíso, 4299; Tamarana, 15848; Figueira, } \\
6465 .\end{array}$ & 270870 \\
\hline Pato Branco & $\begin{array}{l}\text { Rio Bonito do Iguaçu, 49801; Coronel Vivida, 37812*; Chopinzinho, } \\
61833 * \text {. }\end{array}$ & 149446 \\
\hline Ponta Grossa & $\begin{array}{l}\text { Curiúva, 33694; Imbaú 4822; Ipiranga, 13199; Ivaí, 10592; } \\
\text { Jaguariaíva, 25337; Palmeira, 30257; Piraí do Sul, 23656; Reserva, } \\
\text { 87930; Senges, 27271; Telêmaco Borba, 1233; Tibagi, 41182; } \\
\text { Ventania, } 12595 .\end{array}$ & 311768 \\
\hline TOTAL GERAL & 64 & 2347763 \\
\hline
\end{tabular}

Fonte: $\mathrm{O}$ autor. *Dados referentes às reservas indígenas do município.

Aspecto de relevada importância nos resultados obtidos é o fato de que a presença da planta nos respectivos municípios ocupa áreas de tamanho e localidades diferentes. Não constituía objetivo de o levantamento mensurar as áreas, nem tão pouco explorar outros aspectos que não configurassem o objetivo maior do trabalho: a existência da hematúria em bovinos em localidades onde também existe a Pteridium arachnoideum. Assim, é seguro afirmar que a correlação entre elas, já consolidada e referenciada pela literatura mundial permanece como fator direto de manifestações clínicas de "urina sanguinolenta", sobretudo em vacas.

Em outro viés, mas igualmente importante este trabalho volta a alertar sobre a questão da saúde pública, pois onde há vacas com Hematúria Enzoótica é bem provável que haja contaminação do leite de vacas que se alimentam ou já se alimentaram da samambaia, originando enfermidades nos consumidores humanos (Alonso-Amelot, 1996). Esta deverá ser uma política norteadora nos próximos ensaios e levantamentos, havendo a boa e importante cumplicidade dos produtores rurais. Aliado a essas metas, é de suma importância que os produtores rurais sejam conscientizados sobre a correlação direta da existência da planta dentro de suas propriedades com a manifestação da hematúria enzoótica no rebanho, deixando de lado suas crendices e banindo o empirismo terapêutico. Para tal, é imprescindível a atuação 
do médico veterinário nessas localidades, priorizando a profilaxia e a orientação a esses produtores, uma vez que não há medidas de tratamento eficazes para a doença.

\section{Conclusão}

Pelos resultados encontrados no levantamento de dados, permitiu-se visualizar as regiões do estado do Paraná com incidência de Hematúria Enzoótica dos Bovinos em consequência da presença e infestação de pastagens pela Pteridium arachnoideum, popularmente conhecida por samambaia.

\section{Agradecimentos}

Ao extensionista Paulo Tadatoshi Hiroki da EMATER - Empresa Paranaense de Assistência Técnica e Extensão Rural, Regional de Londrina, por ter contribuído de forma relevante e por todo apoio prestado para elaboração deste presente trabalho.

\section{Referências Bibliográficas}

ADAPAR. Rebanho bovino e bubalino por município do Paraná (dados obtidos na campanha de vacinação de novembro de 2011). Agência de Defesa Agropecuária do Paraná. Disponível em <http://www.adapar.pr.gov.br/arquivos/File/d efis/rebanhobovideo.pdf $>$ Acesso em 19 de janeiro de 2016

Alonso-Amelot, M. E. (1996). Bracken ptaquiloside in milk. Food and Chemical Toxicology, 11, 1187.

ANUALPEC. (2014). Anuário da Pecuária Brasileira, 20th edn. Instituto FNP, São Paulo, SP, Brasil.

Basile, J., Reis, A. \& Gaste, L. (1981). Intoxicação aguda de bovinos pela samambaia (Pteridium aquilinum (L) Kuhn), no Estado do Paraná. Revista do Sector de Ciências Agrárias, 3, 167-170.

Carvalho, M. C., Marçal, W. S., Balarin, M. S., Fortes, M. S., Junior, N. P. \& Camargo, M. I. (2011). Avaliação bioquímica do ácido siálico como biomarcador tumoral em novilhas criadas em propriedade endêmica para hematúria enzoótica dos bovinos. Ciência Animal Brasileira, 12, 306-310.

Ferreira, J. (1996). O Paraná e seus mucinípios. Memória Brasileira, 1, 569-570.
Furlan, F. H., Costa, F. L. d., Torres Jr, S., Kerber, F. L., Damasceno, E. S., Salino, A. \& Riet-Correa, F. (2014). Profile of farms with pastures invaded by Pteridium arachnoideum in northern Mato Grosso and prevalence of bovine enzootic hematuria. Pesquisa Veterinária Brasileira, 34, 753-759.

Galvão, A., Brito, M. d. F., Aragão, A. P., Yamasaki, E. M., Peixoto, P. V. \& Tokarnia, C. H. (2012). Sobrevivência/viabilidade de bovinos com Hematúria Enzoótica após transferência para região livre de Pteridium arachnoideum. Pesquisa Veterinaria Brasileira, 32, 887-902.

Hojo-Souza, N., Carneiro, C. \& Santos, R. (2010). Pteridium aquilinum: o que sabemos eo que ainda falta saber. Bioscience Journal, 26, 798-808.

Jankowski, J., Murphy, S., Coghill, G., Grant, A., Wormsley, K., Sanders, D., Kerr, M. \& Hopwood, D. (1992). Epidermal growth factor receptors in the oesophagus. Gut, 33, 439-443.

Lorenzi, H. (1982). Pteridium aquilinum (L) Kuhn. In: Plantas daninhas do Brasil: terrestres, aquáticas, tóxicas e medicinais. Nova Odessa, p.341.

Marçal, W. S. (2000). A toxidez da samambaia nos bovinos. Disponível em <http://www.saudeanimal.com.br/bovino_sam ambaia.htm> Acesso em 19 de janeiro de 2016.

Marçal, W. S. (2003). A intoxicação por samambaia em bovinos criados no estado do Paraná. Semina: Ciências Agrárias, 24, $197-$ 208.

Marçal, W. S., Gaste, L., Netto, N. C. R., Marques, M. C. G., Fernandes, R. P. \& Monteiro, A. A. (2004). Ocorrência de intoxicação aguda em bovinos pela samambaia (Pteridium aquilinum, L. Kuhn) no norte do Paraná-Brasil. Semina: Ciências Agrárias, 22, 139-144.

Marliére, C. A., Santos, R. C. M., Galväo, M. A. M., Soares, J. F., Evangelista, C. L. M. \& Gomes, R. Q. F. (1998). Ingestäo de broto de samambaia e risco de câncer de esôfago e estômago na regiäo de Ouro Preto, MG. Revista Brasileira de Cancerologia, 44, 225229.

Niero, L.; Marçal, W. S.; Reis, A.C.F. \& Accorsi, E. (1991). Surto de intoxicação aguda em 
bovinos pela ingestão de samambaia (Pteridium aquilinum, L. Kuhn) no norte do Paraná. In: $9^{\circ}$ Simpósio de Estagiários do CCB/UEL, (1991), Anais. Londrina. UEL, p.90.

Oinonen, E. (1967). The correlation between the size of finish bracken Pteridium aquilinum (L. Kuhn) clones and certain periods of site story. Acta Forestalia Fennica, 83, 1-51.

Oliveira, G., Matsumoto, T. \& Primavesi, A. (1998). Ocorrência de intoxicação causada por samambaia (Pteridium aquilinum) na Região nordeste do Paraná. Embrapa-Comunicado Técnico, 20, 1-9.

Parker, W. H. \& McCrea, C. T. (1965). Bracken (Pteris aquilina) poisoning of sheep in the north york moors. The Veterinary Record, 77, 861-865.

Polack, E.W. (1990). Toxicidade da Pteridium aquilinum no Estado do Paraná. Dissertação (Mestrado) - Universidade Federal do Paraná, Curitiba.

Reichmann, C. E. (1975). Hematúria enzoótica dos bovinos. São José do Rio Preto, Palestra proferida.

Thomson, J. A., Mickel, J. T. \& Mehltreter, K. (2008). Taxonomic status and relationships of bracken ferns (Pteridium: Dennstaedtiaceae) of Laurasian affinity in Central and North America. Botanical Journal of the Linnean Society, 157, 1-17.
Tokarnia, C. H. (2000). Plantas de ação radiomimética. In: Tokarnia, C. H.; Dobereiner, J.; Peixoto, P. V. Plantas Tóxicas do Brasil. Primeira edição. Editora Helianthus Ltda-ME, p. 178-187.

Tokarnia, C. H.; Dobereiner, J. \& Barros, S. S. (1979). Plantas tóxicas do Brasil. Região Sul. Rio de Janeiro: Universidade Federal Rural do Rio de Janeiro.

Tokarnia, C. H., Döbereiner, J. \& Canella, C. F. (1969). Ocorrência da hematúria enzoótica e de carcinomas epidermóides no trato digestivo superior em bovinos no Brasil. II. Estudos complementares. Pesquisa Agropecuária Brasileira, 4, 209-224.

Ulian, C. M. V., Baptista, A. A. S., Ventura, R. F. A. \& Sakate, M. (2010). Pteridium aquilinum na alimentação humana: uma revisão. Acta Veterinaria Brasilica, 4, 64-69.

Recebido em Outubro 11, 2015

Aceito em Dezembro 2, 2015

License information: This is an open-access article distributed under the terms of the Creative Commons Attribution License, which permits unrestricted use, distribution, and reproduction in any medium, provided the original work is properly cited. 